\title{
The Effects of Dressing up Preterm Infants After Tub Bathing on Moisture Loss: A Randomized Controlled Trial
}

\author{
Zehra Kan Öntürk ${ }^{1}$, Duygu Gözen² \\ ${ }^{1}$ Acıbadem Mehmet Ali Aydınlar University, Faculty of Health Science, Department of Nursing, Istanbul, Turkey \\ ${ }^{2}$ İstanbul University-Cerrahpaşa, Florence Nightingale Faculty of Nursing, Pediatric Nursing Department, Istanbul, Turkey \\ Correspondence Author: Duygu Gözen \\ E-mail: duygugozen@gmail.com
}

Received: 22.08.2019 Accepted: 28.12.2019

\begin{abstract}
Objective: The skin of the preterm newborn plays an important role in adapting the newborn to the environment after birth. This was designed as a randomised controlled experimental trial in order to determine the effect of dressing after tub bathing on loss of skin moisture in healthy preterm infants.

Methods: The population of the study consisted of the infants who were born between 33,0-36,6 weeks of gestation. Skin moisture (forehead, abdomen, back, arm, leg) and body temperature measurements of the infants before bathing, immediately after bathing, and $10,20,30$, and 60th minutes after bathing were assessed.

Results: It was determined that while the moisture was kept and increased in the experimental group, moisture loss occurred in the control group. The infants in both groups had heat loss after the bathing.

Conclusion: It was determined that the skin moisture and body temperature of the experimental group infants were affected positively.

Keywords: Infant; bathing; temperature; moisture; skin.
\end{abstract}

\section{INTRODUCTION}

Maintaining fluid and electrolyte balance in the first days after birth is very difficult particularly in preterm and lowbirth-weight infants. Hidden fluid losses occur as a result of mucous membranes and the evaporation of water from the skin (1).

The characteristics of the skin, the largest organ in the body of preterm infants cause greater fluid loss than term infants. Structure of stratum corneum (SC) is the most important factor in preserving skin moisture and integrity in preterm infants (2). Preterm infants have thinner skin than term infants, their body surface area to body weight ratio is high, their subcutaneous fat tissues are not fully developed, their brown fat tissue is low, their glycogen storage are low, and their stratum corneum layer is thin (3). This causes more transepidermal water loss (TEWL) in preterm infants $(2,4-6)$.

Bathing causes evaporative and transepidermal water loss in infants (4-6). Skin moisture forms a barrier for the infant. Inadequate skin barrier is risky for skin permeability and infant can be exposed to fluid losses, electrolyte imbalance, thermoregulatory impairment, infection, and delayed skin development $(1,7)$.
It is stated in the studies that within the first 10 minutes after the bathing, significant decreases occur in the body temperature of the infant and the clothes dressed right after the bathing get moistened and can cause rapid heat loss due to evaporation after bathing $(8,9)$.

\section{METHODS}

\subsection{Design and setting}

This study was conducted to determine the effect of dressing after tub bathing on loss of skin moisture in healthy preterm infants.

This study was conducted a randomised controlled experimental trial (Figure 1). The randomisation was determined by entering the total number of cases into the program in URL address of https://www.randomizer.org. Before entering the sample size data into the program, it was assumed that the set 1 would represent control group including the infants who were dressed after bathing (DAB) and the set 2 would represent experimental group including the infants who were swaddled after bathing (SAB). 


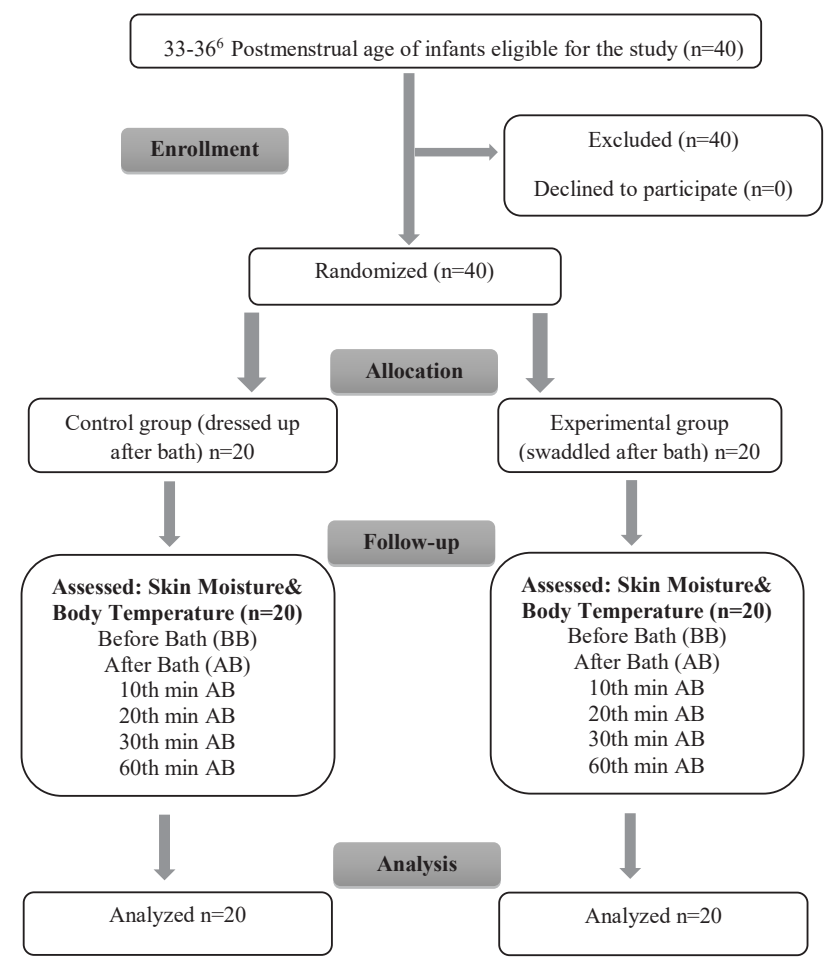

Figure 1. CONSORT Flow Diagram of Randomized Controlled Trial

\subsection{Sample}

The population of the study consisted of the preterm infants having postmenstrual ages of $33^{0}-36^{+6}$ weeks who met the inclusion criteria in NICU.

Before starting the study, written ethics committee approval and institutional permission were obtained from Medical Research Evaluation Board of Acibadem University and Acibadem Health Institutions (2013-509). The legal representatives of all infants were informed about aim, design, and duration of the study and how data would be used by using "Informed Consent Form" and their consents were obtained.

In order to determine the sample size, a priori power analysis was performed by using G*Power (v3.1.7) program. The sample size was calculated by considering the study entitled "The effect of duration of the first bath on body temperature of the infant" conducted by Varda and Behnke (2000); the effect size was found to be 1.89 when measurements taken at $10^{\text {th }}$ minute before and after the bathing were evaluated in both groups.

When the power of the study was requested to be (1- $\beta$ ) 0.80 ; it was determined to include 30 cases, including 15 homogeneous ones in both groups, in the sample group. By taking possible case losses into consideration, a total of 40 preterm infants were planned to be included in the study.

The inclusion criteria for the sample group:

Preterm infants whose parents were voluntary to participate in the study,
Those who were considered as healthy by the physician,

Those who had stable physiological condition,

Those who had no congenital abnormality and underwent no surgical procedure,

Those who had a postmenstrual age of $33^{0}-36^{+6}$.

The data of the study were collected at NICU of a private hospital in Istanbul between November 2013 and December 2015. In this unit, every infant is bathed before discharge, and the mothers are synchronously trained about infant bathing.

\subsection{Measurements}

The data collection form including the study application steps as a check list was prepared by the researchers in order to record the data of the study and perform the same bathing steps in every infant by guiding the researcher during the study. The form was sent to 14 pediatric nurses professionals and the form was revised in accordance with their suggestions.

The data collection form involved;

Descriptive information about the infant and family,

A check list containing room temperature, room humidity, air movement, depth and temperature of bath water, and duration of bathing to control the environmental factors,

A check list to control the materials to be used during and after the bathing,

A table for recording skin moisture and body temperature recorded based on the time intervals determined before and after the bathing.

A calibrated General Electric Carescape B650 model monitor was used to measure oxygen saturation and heart rate; a calibrated Welch Allyn digital axillary thermometer was used to measure body temperature, a calibrated TFA DOSTMANN TFA 30.5002 model thermometer and moisture meter was used to control the room temperature and mositure; and Arzum bebbe AR 857 model bath thermometer was used to measure water temperature before the bathing.

The "DMM-Digital Moisture Monitor For Skin" was used to measure skin moisture loss of infants. This device developed especially for precise measurement was preferred since it can show the moisture amount only through touching without giving any harm on the skin, is wireless, and has a wide measuring range (it can measure the moisture amount of the skin from $0 \%$ to $99.9 \%$ ).

All infants were dressed with $100 \%$ cotton, identical standard baby clothes of the hospital and thin baby blanket and infantspecific gel skin cleanser with neutral pH used by the hospital as a standard in all infants during the bathing were used.

Bathing was performed in the bathroom unit equipped with standard materials including care materials, bathtub, thermostatic battery, and drying and dressing sections. 


\subsection{Procedure}

Each of the infants included in the study was healthy and their physiological condition was stable. The physiological condition of all infants was monitored for 24 hours before the bathing and the bathing was applied after the neonatolog stated that they were healthy and stable. The infants in both groups were bathed one hour after breastfeeding.

In the data collection process, two different dressing methods were applied to the infants included in the study. In the unit where the study was conducted, the infants are dried and dressed immediately after they are routinely bathed. For this reason, the control group of the study consisted of the infants dried and dressed immediately after the bathing $(n=20)$ (Figure 2). The infants included in the experimental group were dried after the bathing and fastened the diaper by putting a cap on their heads. These infants were not dressed but they were swaddled with a double - layered blanket (Figure 3), they were taken onto the open crib, and they were dressed 10 minutes later $(n=20)$.

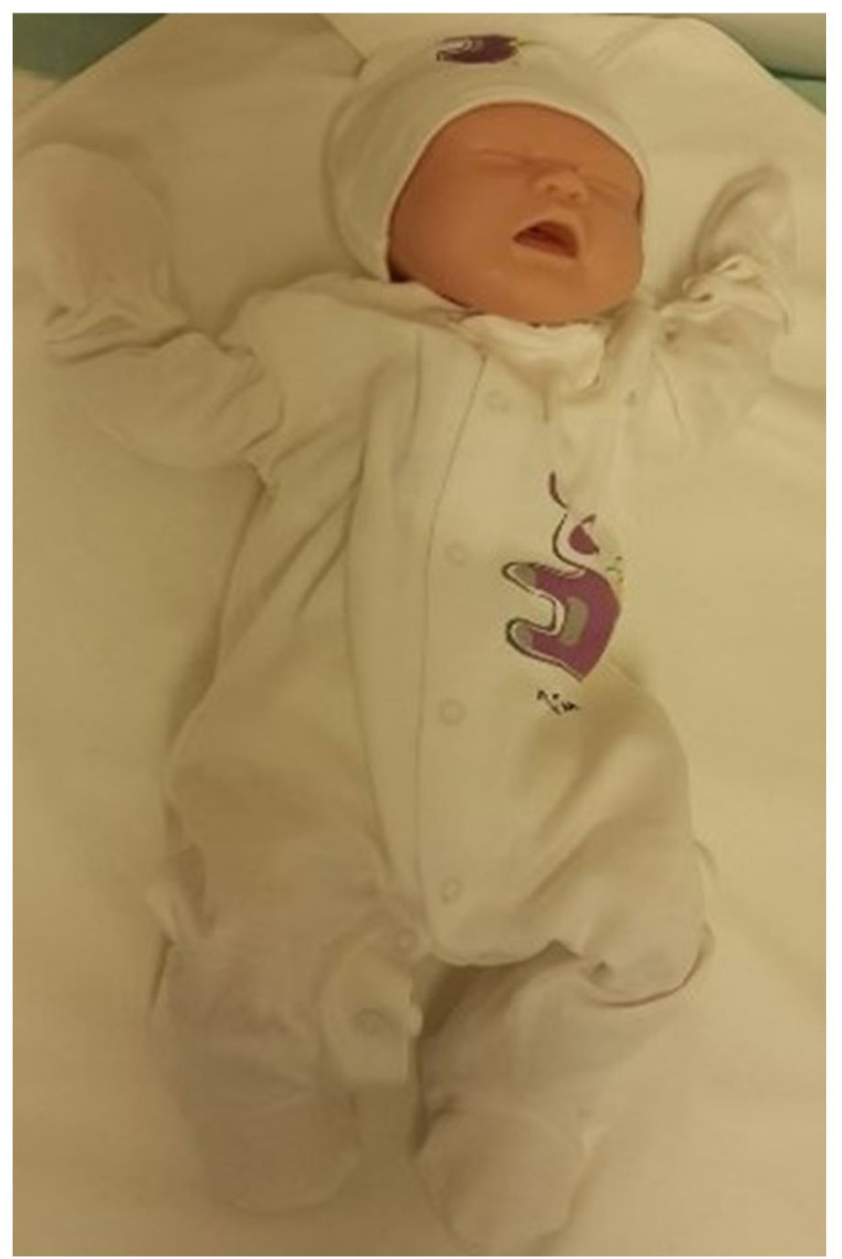

Figure 2. Dressing of control group newborn infants after bath

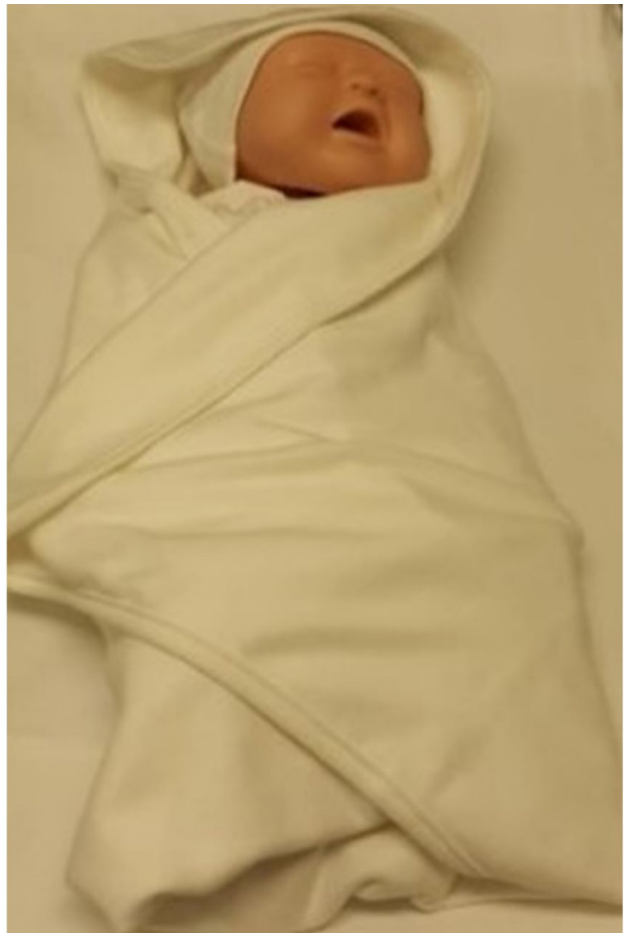

Figure 3. Swaddled experimental group newborn infants after bath

\section{Step 1: Before the Bathing (BB)}

Before the data collection, legal representatives of the infants were informed by using the informed consent and voluntary ones were included in the study.

Variables were controlled. Environmental variables (room temperature: $26-27^{\circ} \mathrm{C}$; humidity: $40-60 \%$; Temperature of bath water: $38{ }^{\circ} \mathrm{C}$ ) in both experimental and control groups were adjusted in the same way. By keeping the door closed in the room where the infants were bathed, the heat loss induced by airflow and convection was minimised.

After measuring and recording body temperature, oxygen saturation, pulse, and the skin moisture from forehead, abdomen, back, arm, and leg regions before the bathing for the infants of both groups, the infants were disconnected from the monitor. They were swaddled in blanket.

\section{Step 2: The Bathing}

Duration of bathing in both groups was less than 5 minutes and bathing performed by the researcher. All infants were slowly placed into the bathtub as swaddled with a thin $100 \%$ cotton blanket. Their head was supported by practitioner only under shoulders in the way to keep the head up.

\section{Step 3: After the Bathing}

After the bathing, all infants were immediately dried with towels and the wet towels were removed from them. They were diapered, put a cap on their head. After this step, experimental group infants were swaddled and control groups were dressed. Skin moisture (forehead, abdomen, back, arm, leg) and body temperature measurements of the 
infants before bathing, immediately after bathing, and 10 , 20,30 , and 60th minutes after bathing were recorded.

\subsection{Statistical analysis}

The NCSS (Number Cruncher Statistical System) 2007 (Kaysville, Utah, USA) programme was used for statistical analysis while evaluating the results obtained from the study. The results were evaluated at confidence interval of $95 \%$ and significance level of $p<0.05$.

\section{RESULTS}

No statistically significant difference was found between the groups in terms of gender, gestational age at birth, postmenstrual age, APGAR score $\left(1^{\text {st }} \mathrm{min}\right.$. and $\left.5^{\text {th }} \mathrm{min}.\right)$, physical characteristics at birth and before the bathing (body weight, height, head circumference), physiological characteristics before the bathing (body temperature, heart rate, $\mathrm{O}_{2}$ saturation), and duration of bathing (Table $1 ; \mathrm{p}>0.05$ ).

Table 1. Infants' Descriptive Characteristics and Comparison of their Descriptive Characteristics based on the Groups ( $N=40)$

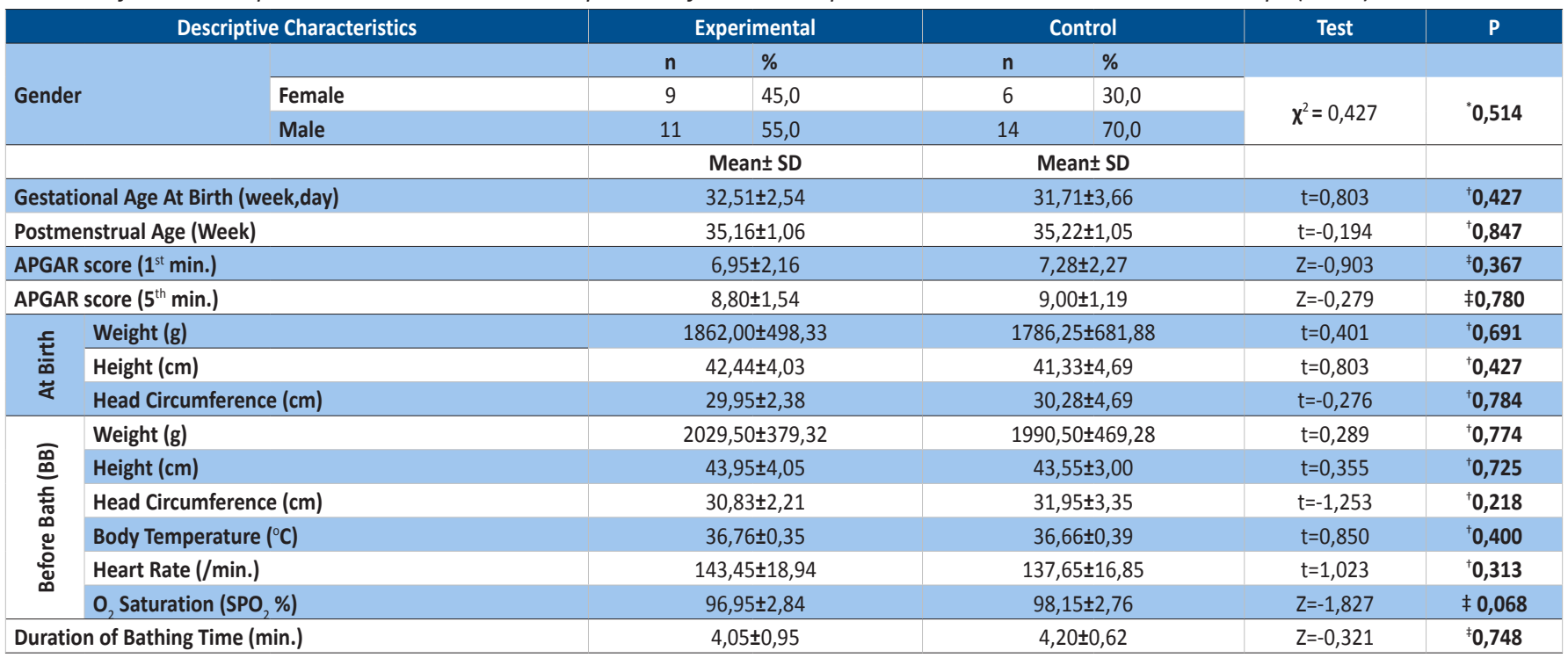

"Yates Continuity Correction Test + Student-t Test $¥$ Mann Whitney $\cup$ Test

When the groups were compared in terms of moisture averages according to before and after bathing, no statistically significant difference was found between the groups (Table $2 ; \mathrm{p}>0.05$ ).

Table 2. Comparison of skin moisture measurement averages of body regions (forehead, abdomen, back, arm, leg) according to different dressing applications $(\mathrm{N}=40)$

\begin{tabular}{|c|c|c|c|c|c|c|c|c|c|c|c|}
\hline \multirow{3}{*}{\multicolumn{2}{|c|}{ Measurement time }} & \multicolumn{10}{|c|}{ Skin Moisture Measurement (\%) } \\
\hline & & \multicolumn{2}{|c|}{ Forehead } & \multicolumn{2}{|c|}{ Abdomen } & \multicolumn{2}{|c|}{ Back } & \multicolumn{2}{|c|}{ Arm } & \multicolumn{2}{|c|}{ Leg } \\
\hline & & Exp. & Control & Exp. & Control & Exp. & Control & Exp. & Control & Exp. & Control \\
\hline \multirow[b]{2}{*}{ BB } & Mean \pm SD & $31,36 \pm 4,86$ & $31,98 \pm 5,60$ & $33,93 \pm 3,56$ & $35,05 \pm 4,87$ & $31,79 \pm 2,18$ & $34,01 \pm 6,52$ & $30,33 \pm 4,71$ & $32,14 \pm 4,31$ & $29,23 \pm 3,87$ & $30,73 \pm 2,91$ \\
\hline & Test $t p$ & \multicolumn{2}{|c|}{$\begin{array}{c}-0,374 \\
\mathbf{0 , 7 1 0}\end{array}$} & \multicolumn{2}{|c|}{$\begin{array}{c}-0,827 \\
0,413\end{array}$} & \multicolumn{2}{|c|}{$\begin{array}{l}-1,448 \\
\mathbf{0 , 1 5 6}\end{array}$} & \multicolumn{2}{|c|}{$\begin{array}{l}-1,273 \\
\mathbf{0 , 2 1 1}\end{array}$} & \multicolumn{2}{|c|}{$\begin{array}{l}-1,392 \\
\mathbf{0 , 1 7 2}\end{array}$} \\
\hline \multirow{2}{*}{$\begin{array}{l}\text { After } \\
\text { Bath } \\
\text { (AB) }\end{array}$} & Mean \pm SD & $35,84 \pm 4,39$ & $34,86 \pm 6,22$ & $36,67 \pm 5,28$ & $35,93 \pm 5,21$ & $34,12 \pm 4,58$ & $34,99 \pm 4,82$ & $34,35 \pm 6,33$ & $32,78 \pm 3,17$ & $32,65 \pm 3,80$ & $33,93 \pm 5,03$ \\
\hline & Test $t p$ & \multicolumn{2}{|c|}{$\begin{array}{c}0,573 \\
0,57\end{array}$} & \multicolumn{2}{|c|}{$\begin{array}{c}0,443 \\
0,66\end{array}$} & \multicolumn{2}{|c|}{$\begin{array}{l}-0,585 \\
0,562 \\
\end{array}$} & \multicolumn{2}{|c|}{$\begin{array}{l}0,992 \\
0,328\end{array}$} & \multicolumn{2}{|c|}{$\begin{array}{l}-0,912 \\
\mathbf{0 , 3 6 8} \\
\end{array}$} \\
\hline \multirow[b]{2}{*}{$10^{\text {th }} \min$} & Mean \pm SD & $31,28 \pm 4,69$ & $31,94 \pm 3,91$ & $34,08 \pm 4,84$ & $32,92 \pm 2,83$ & $31,38 \pm 3,09$ & $32,40 \pm 1,95$ & $30,26 \pm 3,95$ & $31,03 \pm 3,35$ & $29,73 \pm 2,17$ & $31,07 \pm 3,22$ \\
\hline & Test $t p$ & \multicolumn{2}{|c|}{$\begin{array}{l}-0,483 \\
0,632\end{array}$} & \multicolumn{2}{|c|}{$\begin{array}{l}0,930 \\
0,358\end{array}$} & \multicolumn{2}{|c|}{$\begin{array}{l}-1,254 \\
\mathbf{0 , 2 1 7}\end{array}$} & \multicolumn{2}{|c|}{$\begin{array}{l}-0,669 \\
0,507\end{array}$} & \multicolumn{2}{|c|}{$\begin{array}{c}-1,542 \\
\mathbf{0 , 1 3 1}\end{array}$} \\
\hline \multirow[b]{2}{*}{$20^{\text {th }} \min$} & Mean \pm SD & $32,69 \pm 4,93$ & $31,95 \pm 3,26$ & $32,10 \pm 4,81$ & $32,03 \pm 2,68$ & $31,95 \pm 2,14$ & $32,38 \pm 2,75$ & $30,72 \pm 2,64$ & $28,74 \pm 3,45$ & $28,36 \pm 3,89$ & $29,44 \pm 3,06$ \\
\hline & Test $+p$ & \multicolumn{2}{|c|}{0,560} & \multicolumn{2}{|c|}{0,053} & \multicolumn{2}{|c|}{$\begin{array}{c}-0,552 \\
\mathbf{0 , 5 8 4}\end{array}$} & \multicolumn{2}{|c|}{$\begin{array}{c}2,045 \\
0,048^{* *}\end{array}$} & \multicolumn{2}{|c|}{$\begin{array}{l}-0,976 \\
0,335\end{array}$} \\
\hline \multirow[b]{2}{*}{$30^{\text {th }} \min$} & Mean \pm SD & $31,14 \pm 2,17$ & $30,91 \pm 4,14$ & $32,31 \pm 4,98$ & $32,24 \pm 2,43$ & $31,82 \pm 1,59$ & $32,32 \pm 2,68$ & $28,61 \pm 3,34$ & $29,70 \pm 4,14$ & $28,42 \pm 4,30$ & $29,57 \pm 3,54$ \\
\hline & Test $+p$ & \multicolumn{2}{|c|}{$\begin{array}{l}0,220 \\
0,827\end{array}$} & \multicolumn{2}{|c|}{$\begin{array}{l}0,052 \\
0,958\end{array}$} & \multicolumn{2}{|c|}{$\begin{array}{l}-0,717 \\
0,478\end{array}$} & \multicolumn{2}{|c|}{$\begin{array}{l}-0,917 \\
0,365\end{array}$} & $\begin{array}{l}-0, \\
0,\end{array}$ & \\
\hline & Mean \pm SD & $32,42 \pm 5,52$ & $31,69 \pm 4,26$ & $33,09 \pm 4,99$ & $31,67 \pm 2,17$ & $31,18 \pm 1,76$ & $31,72 \pm 3,44$ & $28,76 \pm 3,13$ & $30,24 \pm 2,20$ & $29,58 \pm 3,51$ & $29,64 \pm 3,01$ \\
\hline $60^{\text {th }} \mathrm{min}$ & Test $t p$ & & & & & & & & & & \\
\hline
\end{tabular}

+ Student-t Test ${ }^{* *} p<0,01$ 
When moisture values in the arm region of the infants and the variation difference of moisture values were compared between the groups, a statistically significant difference was observed only at $20^{\text {th }}$ minute in terms of moisture averages (Table $\left.2 ; p<0.05\right)$ and the variation differences (Table $3 ; p<0.05$ ).

Table 3. Comparison of moisture variation difference values of body regions (forehead, abdomen, back, arm, leg) of the infants according to different dressing applications $(N=40)$

\begin{tabular}{|c|c|c|c|c|c|c|c|c|c|c|c|}
\hline \multirow{3}{*}{\multicolumn{2}{|c|}{ Measurement time }} & \multicolumn{10}{|c|}{ Skin Moisture Measurement (\%) } \\
\hline & & \multicolumn{2}{|c|}{ Forehead } & \multicolumn{2}{|c|}{ Abdomen } & \multicolumn{2}{|c|}{ Back } & \multicolumn{2}{|c|}{ Arm } & \multicolumn{2}{|c|}{ Leg } \\
\hline & & Exp. & Control & Exp. & Control & Exp. & Control & Exp. & Control & Exp. & Control \\
\hline \multirow{3}{*}{ BB-AB } & Difference & $4,48 \pm 4,46$ & $2,88 \pm 6,21$ & $2,74 \pm 5,21$ & $0,89 \pm 4,38$ & $2,34 \pm 4,25$ & $0,98 \pm 7,75$ & $4,02 \pm 8,00$ & $0,64 \pm 4,55$ & $3,42 \pm 4,94$ & $3,20 \pm 3,53$ \\
\hline & $\S p$ & $0,004^{* *}$ & 0,777 & 0,449 & 1,000 & 0,357 & 1,000 & 0,552 & 1,000 & 0,089 & $0,010^{*}$ \\
\hline & $\begin{array}{l}\text { Test } \\
\text { tp }\end{array}$ & \multicolumn{2}{|c|}{$\begin{array}{c}-0,933 \\
0,357\end{array}$} & \multicolumn{2}{|c|}{$\begin{array}{c}-1,216 \\
\mathbf{0 , 2 3 2}\end{array}$} & \multicolumn{2}{|c|}{$\begin{array}{l}-0,685 \\
\mathbf{0 , 4 9 7}\end{array}$} & \multicolumn{2}{|c|}{$\begin{array}{c}-1,645 \\
\mathbf{0 , 1 1}\end{array}$} & \multicolumn{2}{|c|}{$\begin{array}{l}-0,162 \\
0,872\end{array}$} \\
\hline \multirow{3}{*}{ BB-10 $10^{\text {th }}$ in } & Difference & $-0,08 \pm 4,62$ & $-0,04 \pm 5,10$ & $0,15 \pm 5,56$ & $-2,13 \pm 3,66$ & $-0,41 \pm 3,01$ & $-1,61 \pm 6,66$ & $-0,07 \pm 5,92$ & $-1,11 \pm 6,70$ & $0,50 \pm 4,26$ & $0,34 \pm 3,25$ \\
\hline & $\S p$ & 1,000 & 1,000 & 1,000 & 0,261 & 1,000 & 1,000 & 1,000 & 1,000 & 1,000 & 1,000 \\
\hline & $\begin{array}{l}\text { Test } \\
+p\end{array}$ & \multicolumn{2}{|c|}{$\begin{array}{l}0,026 \\
0,979\end{array}$} & \multicolumn{2}{|c|}{$\begin{array}{l}-1,532 \\
\mathbf{0 , 1 3 4}\end{array}$} & \multicolumn{2}{|c|}{$\begin{array}{l}-0,735 \\
0,467\end{array}$} & \multicolumn{2}{|c|}{$\begin{array}{c}-0,520 \\
\mathbf{0 , 6 0 6}\end{array}$} & \multicolumn{2}{|c|}{$\begin{array}{c}-0,138 \\
\mathbf{0 , 8 9 1}\end{array}$} \\
\hline \multirow{3}{*}{ BB-20 ${ }^{\text {th }}$ min } & Difference & $1,33 \pm 5,95$ & $-0,04 \pm 5,53$ & $-1,84 \pm 4,50$ & $-3,02 \pm 4,48$ & $0,16 \pm 2,13$ & $-1,64 \pm 6,49$ & $0,40 \pm 5,13$ & $-3,41 \pm 6,01$ & $-0,87 \pm 4,11$ & $-1,29 \pm 3,11$ \\
\hline & $\S p$ & 1,000 & 1,000 & 1,000 & 0,108 & 1,000 & 1,000 & 1,000 & 0,306 & 1,000 & 1,000 \\
\hline & $\begin{array}{l}\text { Test } \\
+p\end{array}$ & \multicolumn{2}{|c|}{$\begin{array}{c}-0,749 \\
0,459\end{array}$} & \multicolumn{2}{|c|}{$\begin{array}{c}-0,831 \\
0,411\end{array}$} & \multicolumn{2}{|c|}{$\begin{array}{r}-1,175 \\
\mathbf{0 , 2 4 7} \\
\end{array}$} & \multicolumn{2}{|c|}{$\begin{array}{c}-2,148 \\
0,038^{* *}\end{array}$} & \multicolumn{2}{|c|}{$\begin{array}{c}-0,368 \\
0,715\end{array}$} \\
\hline \multirow{3}{*}{ BB-30 ${ }^{\text {th }}$ min } & Difference & $-0,22 \pm 4,23$ & $-1,07 \pm 7,87$ & $-1,63 \pm 4,76$ & $-2,81 \pm 4,10$ & $0,03 \pm 2,36$ & $-1,70 \pm 6,06$ & $-1,72 \pm 4,49$ & $-2,44 \pm 5,86$ & $-0,81 \pm 1,16$ & $-3,90 \pm 2,58$ \\
\hline & $\S p$ & 1,000 & 1,000 & 1,000 & 0,097 & 1,000 & 1,000 & 1,000 & 1,000 & 1,000 & 0,882 \\
\hline & $\begin{array}{l}\text { Test } \\
t p\end{array}$ & \multicolumn{2}{|c|}{$\begin{array}{l}-0,425 \\
\mathbf{0 , 6 7 3}\end{array}$} & \multicolumn{2}{|c|}{$\begin{array}{c}-0,840 \\
0,406\end{array}$} & \multicolumn{2}{|c|}{$\begin{array}{r}-1,187 \\
\mathbf{0 , 2 4 3}\end{array}$} & \multicolumn{2}{|c|}{$\begin{array}{c}-0,439 \\
\mathbf{0 , 6 6 3}\end{array}$} & \multicolumn{2}{|c|}{$\begin{array}{l}-0,340 \\
0,736\end{array}$} \\
\hline \multirow{3}{*}{ BB-60 $0^{\text {th }}$ min } & Difference & $1,06 \pm 5,96$ & $-0,30 \pm 6,38$ & $-0,85 \pm 5,64$ & $-3,37 \pm 4,17$ & $-0,61 \pm 1,97$ & $-2,29 \pm 6,09$ & $-1,57 \pm 4,49$ & $-1,90 \pm 4,31$ & $0,35 \pm 4,40$ & $-1,09 \pm 3,21$ \\
\hline & $\S p$ & 1,000 & 1,000 & 1,000 & $0,028^{*}$ & 1,000 & 1,000 & 1,000 & 0,952 & 1,000 & 1,000 \\
\hline & $\begin{array}{l}\text { Test } \\
\text { tp }\end{array}$ & \multicolumn{2}{|c|}{$\begin{array}{c}-0,694 \\
0,492\end{array}$} & \multicolumn{2}{|c|}{$\begin{array}{c}-1,611 \\
\mathbf{0 , 1 1 5}\end{array}$} & & & $\begin{array}{l}-0, \\
0,\end{array}$ & & & \\
\hline
\end{tabular}

tStudent-t Test §Bonferroni Test ${ }^{* *} p<0,01$

There was no statistically significant difference between the groups in terms of whole body moisture averages as well as the variation difference of whole body moisture values (Table $4 ; p>0.05$ ).

Table 4. Comparison of all body skin moisture measurement averages and moisture variation difference values of the infants according to different dressing applications $(N=40)$

\begin{tabular}{|c|c|c|c|c|}
\hline \multirow[b]{2}{*}{ Measurement time } & \multicolumn{2}{|c|}{ Skin Moisture Measurement (\%) } & \multirow[b]{2}{*}{ Test } & \multirow[b]{2}{*}{$t p$} \\
\hline & $\begin{array}{c}\text { Experimental } \\
\text { Mean } \pm \text { SD }\end{array}$ & $\begin{array}{c}\text { Control } \\
\text { Meant SD }\end{array}$ & & \\
\hline BB & $31,33 \pm 2,55$ & $32,78 \pm 3,56$ & $-1,487$ & 0,145 \\
\hline$A B$ & $34,72 \pm 3,53$ & $34,50 \pm 4,02$ & 0,188 & 0,852 \\
\hline $10^{\text {th }} \min$ & $31,34 \pm 2,76$ & $31,87 \pm 1,89$ & $-0,705$ & 0,485 \\
\hline $20^{\text {th }} \min$ & $31,16 \pm 2,44$ & $30,91 \pm 1,77$ & 0,380 & 0,706 \\
\hline $30^{\text {th }} \min$ & $30,46 \pm 2,34$ & $30,95 \pm 2,34$ & $-0,660$ & 0,513 \\
\hline $60^{\text {th }} \min$ & $31,00 \pm 2,46$ & $30,99 \pm 2,05$ & 0,017 & 0,986 \\
\hline \multirow{2}{*}{$\begin{array}{l}\text { Test } \\
\text { "Ip }\end{array}$} & 14,311 & 6,557 & & \\
\hline & $0,001 * *$ & $0,002 * *$ & & \\
\hline \multirow{2}{*}{$\begin{array}{l}\text { BB-AB } \\
\S p\end{array}$} & $3,40 \pm 3,20$ & $1,72 \pm 4,19$ & \multirow{2}{*}{$-1,426$} & \multirow{2}{*}{0,162} \\
\hline & $0,002 * *$ & 1,000 & & \\
\hline \multirow{2}{*}{$\begin{array}{l}\text { BB-10 } 10^{\text {th }} \min \\
\S p\end{array}$} & $0,02 \pm 2,10$ & $-0,91 \pm 3,30$ & \multirow{2}{*}{$-1,062$} & \multirow{2}{*}{0,295} \\
\hline & 1,000 & 1,000 & & \\
\hline \multirow{2}{*}{$\begin{array}{l}\text { BB-20 } 0^{\text {th }} \min \\
\S p\end{array}$} & $-0,16 \pm 2,17$ & $-1,88 \pm 3,17$ & \multirow{2}{*}{$-1,991$} & \multirow{2}{*}{0,054} \\
\hline & 1,000 & 0,239 & & \\
\hline \multirow{2}{*}{$\begin{array}{l}\text { BB- } 30^{\text {th }} \min \\
\S p\end{array}$} & $-0,87 \pm 2,02$ & $-1,83 \pm 3,69$ & \multirow{2}{*}{$-1,027$} & \multirow{2}{*}{0,311} \\
\hline & 1,000 & 0,580 & & \\
\hline \multirow{2}{*}{$\begin{array}{l}\text { BB-10 } 10^{\text {th }} \min \\
\S p\end{array}$} & $-0,32 \pm 2,61$ & $-1,79 \pm 2,92$ & \multirow{2}{*}{$-1,679$} & \multirow{2}{*}{0,101} \\
\hline & 1,000 & 0,194 & & \\
\hline +Student-t Test & Test & $* * p<0,01$ & & \\
\hline
\end{tabular}


It was found that there was no statistically significant difference between the groups in terms of the mean body temperatures and body temperature variation differences evaluated due to measurement times (Table 5; $p>0.05$ ).

Table 5. Comparison of body temperature averages and body temperature variation difference values of the infants according to different dressing applications $(N=40)$

\begin{tabular}{|c|c|c|c|c|}
\hline \multirow[b]{2}{*}{ Measurement time } & \multicolumn{2}{|c|}{ Body Temperature $\left({ }^{\circ} \mathrm{C}\right)$} & \multirow[b]{2}{*}{ Test } & \multirow[b]{2}{*}{$t p$} \\
\hline & $\begin{array}{l}\text { Experimental } \\
\text { Mean } \pm \text { SD }\end{array}$ & $\begin{array}{l}\text { Control } \\
\text { Meant SD }\end{array}$ & & \\
\hline BB & $36,78 \pm 0,36$ & $36,68 \pm 0,39$ & 0,885 & 0,382 \\
\hline$A B$ & $36,50 \pm 0,42$ & $36,47 \pm 0,35$ & 0,244 & 0,809 \\
\hline $10^{\text {th }} \min$ & $36,53 \pm 0,35$ & $36,50 \pm 0,36$ & 0,270 & 0,789 \\
\hline $20^{\text {th }} \min$ & $36,66 \pm 0,26$ & $36,49 \pm 0,33$ & 1,812 & 0,078 \\
\hline $30^{\text {th }} \mathrm{min}$ & $36,60 \pm 0,31$ & $36,59 \pm 0,35$ & 0,143 & 0,887 \\
\hline $60^{\text {th }} \min$ & $36,77 \pm 0,27$ & $36,63 \pm 0,39$ & 1,313 & 0,197 \\
\hline \multirow{2}{*}{$\begin{array}{l}\text { Test } \\
\| p\end{array}$} & 3,005 & 2,485 & & \\
\hline & $0,045^{*}$ & 0,079 & & \\
\hline \multirow{2}{*}{$\begin{array}{l}\text { BB-AB } \\
\S p\end{array}$} & $-0,29 \pm 0,47$ & $-0,21 \pm 0,36$ & \multirow{2}{*}{0,571} & \multirow{2}{*}{0,572} \\
\hline & 0,203 & 0,240 & & \\
\hline \multirow{2}{*}{$\begin{array}{l}\text { BB-10 } 0^{\text {th }} \text { min } \\
\S p\end{array}$} & $-0,25 \pm 0,32$ & $-0,18 \pm 0,38$ & \multirow{2}{*}{0,671} & \multirow{2}{*}{0,506} \\
\hline & $0,038^{*}$ & 0,821 & & \\
\hline \multirow{2}{*}{$\begin{array}{l}\text { BB-20 } 0^{\text {th }} \text { min } \\
\S p\end{array}$} & $-0,12 \pm 0,35$ & $-0,19 \pm 0,32$ & \multirow{2}{*}{$-0,613$} & \multirow{2}{*}{0,544} \\
\hline & 1,000 & 0,296 & & \\
\hline \multirow{2}{*}{$\begin{array}{l}\text { BB-30 } 30^{\text {th }} \min \\
\S p\end{array}$} & $-0,18 \pm 0,49$ & $-0,09 \pm 0,44$ & \multirow{2}{*}{0,614} & \multirow{2}{*}{0,543} \\
\hline & 1,000 & 1,000 & & \\
\hline \multirow{2}{*}{$\begin{array}{l}\text { BB-10 } 10^{\text {th }} \min \\
\S p\end{array}$} & $-0,02 \pm 0,40$ & $-0,05 \pm 0,43$ & \multirow{2}{*}{$-0,266$} & \multirow{2}{*}{0,792} \\
\hline & 1,000 & 1,000 & & \\
\hline
\end{tabular}

tStudent- $t$ Test $\quad$ "Repeated Measure Anova Test $\S$ Bonferroni Test $\quad{ }^{*} p<0,05$

\section{DISCUSSION}

There are numerous studies and guidelines on creation of appropriate conditions and methods within the scope of skin care practices of infants, protection and strengthening of skin barrier, prevention of TEWL and hypothermia $(5,10$ 15 ) in order to bring risks under control and thus prevent complications $(2,16)$. In addition, Blume-Peytavi et al., have reported that there is a need for further researches with high evidence level (17). In accordance with literature (18) 33.036.6 week-old preterm infants with low hypothermia risk were included in the study (Tablo 1 ).

It is reported in the literature that bathing affects physiological characteristics $(5,9,17,19-23)$ and thus physiological condition of infants should be stable before bathing $(2,19)$. It was determined that the infants included in the study had physiological characteristics similar to those stated in the literature $(23,24)$ and there was no harm for bathing (Table 1 ).

In the study conducted by Kim and Park on term infants, they reported that duration of bathing was approximately 3 minutes (24). Bathing duration of the infants included in the study was limited as similar to the duration stated in the literature (2) One of the strengths of the data is that duration of bathing in both groups is similar both to the literature and between the groups (Table 1).
In the moisture evaluation made for each region before the bathing, it was found that the highest moisture value was observed in abdomen region in both experimental and control groups; whereas, the lowest moisture value was observed in leg region in both groups. This result was remarkable in terms of reliability of the data (Table 2 ). In a study investigating the effect of radiant heater on TEWL and skin hydration and comparing 31.6 week-old preterm infants having an average weight of $1588 \mathrm{~g}$ with those receiving care in the incubator, it was reported that there was no statistically significant difference in the other regions except for abdomen region in terms of stratum corneum hydration (18). When the results of the present study were compared with results of Maayan-Metzger et al.'s study, similarly it was observed that moisture level of abdomen was higher than the other body regions.

It was determined in a study comparing two bathing methods in healthy term infants that those bathed using a wetted washcloth twice a week had the highest TEWL in the hip region compared to those bathed normally and the highest SC hydration was obtained from abdomen and forehead (21). In the present study, it was found that while the highest moisture value was obtained in abdomen region, the lowest moisture value was obtained in the leg region before the bathing. This result is similar to Garcia Bartels et al.,'s study, and supports that there is more hydration in the abdomen region.

When the infants' body moisture average differences before and after the bathing were compared, it was observed that the moisture values increased in both groups and the difference in the experimental group was higher than the control group. However, the increase difference in the moisture level was not statistically significant. This increase in body moisture average within the first 10 minutes after bathing was associated with the fact that the body got wet during the bathing, thus, the skin got moisturized by absorbing the water and the highest evaporation occurred within the first 10 minutes after the bathing (Table 3).

The fact that there were the increase in the experimental group and moisture loss in the control group regarding the difference of the whole body moisture average at $10^{\text {th }}$ minute after bathing (Table 4) was not statistically significant; however it was determined that the skin moisture of the infants from the experimental group dressed after being swaddled with the blanket for ten minutes after the bathing increased; whereas, the skin moisture of the control group decreased.

In the present study, it was determined as a result of withingroup measurements that the whole body moisture condition changed significantly in both groups until $60^{\text {th }}$ minute after the bathing (Table 4). When examining the differences between the measurements, it was observed that moisture decreased mostly at $30^{\text {th }}$ minute in the experimental group and at $20^{\text {th }}$ minute in the control group. Additionally, while maximum decrease difference in the control group was $-1.88 \pm 3.17$, the decrease difference was $-0.87 \pm 2.02$ in the 
experimental group (Table 3). In accordance with all these data, it was thought that the intervention of swaddling with the blanket for 10 minutes after the bathing was affected the skin moisture positively even though this was not statistically significant.

It was determined that the infants lost heat after bath in both groups (Table 5). Body temperature values right after the bath and at $10^{\text {th }}$ minute showed a similar decrease in both groups. The experimental group almost reached their pre-bath body temperature at $60^{\text {th }}$ minute; whereas, control group did not reach the pre-bath body temperature at $60^{\text {th }}$ minute.

In the study conducted by Edraki et al., to investigate the effect of swaddle bathing and traditional bathing methods on crying duration and body temperature in preterm infants, they determined that body temperature of the group dressed right after the swaddle bathing, was $36.50^{\circ} \mathrm{C}$ before the bathing and $36.42^{\circ} \mathrm{C}$ at $10^{\text {th }}$ minute after the bathing, and the variation difference between values obtained before the bathing and at $10^{\text {th }}$ minute after the bathing was $-0.09{ }^{\circ} \mathrm{C}$. The results supported that the body temperature decreased during and after the bathing, which was similar to the present study (Table 5) (25).

It was also reported in the study by Kim and Park that the body temperature decreased immediately after the bathing and the group dressed with a cap reached to the pre-bath body temperature within 90 minutes and the group without a cap reached this value within 180 minutes (24). In another study, it was stated that when the time of preterm infants to return to the body temperature after the bathing was examined, the body temperature of only $43 \%$ of the infants reached to $36.5^{\circ} \mathrm{C}$ within 60 minutes and $70 \%$ of them reached to the same temperature within 120 minutes (26). Based on these results, it was observed that putting a cap on infants has an effect on time of return to body temperature. Similar to the results of these studies $(24,26)$ in the present study, it was determined that the group dressed, worn with a new cap and swaddled in double - layered blanket for 10 minutes after the bathing almost reached the pre-bath body temperature at $60^{\text {th }}$ minute; whereas, the control group dressed immediately after the bathing did not reach to the pre-bath body temperature at $60^{\text {th }}$ minute, yet (Table 5). As a result, dressing infants after being dried, put a cap on, and swaddled with blanket for 10 minutes after the bathing and then by changing their cap is a method helping to maintain body temperature and ensure the thermal stability in a shorter time among infants.

\section{CONCLUSION}

There was no statistically significant difference between the effects of dressing immediately after tub bathing and dressing after drying and swaddling with a blanket for ten minutes after the bathing on skin moisture loss and body temperature.

However, stable and increased moisture in the experimental group and moisture loss in control group in the variation change occurring in the whole body moisture at $10^{\text {th }}$ minute showed that the application caused less skin moisture loss. This was not statistically significant between the groups, which suggested that the result was associated with the small sample size. The data obtained about the body temperature within the scope of the study showed that the body temperature of infants decreased in both dressing applications after the bathing. However, it was observed that the body temperature of the infants dressed at the $10^{\text {th }}$ minute after the bathing got closer to the pre-bath value at $60^{\text {th }}$ minute compared to the infants dressed right after the bathing.

In accordance with all these data, it was determined that the skin moisture and body temperature of the infants in experimental group were affected positively even though this was not statistically significant.

Acknowlegement: This study is presented in 2nd Congress of Joint European Neonatal Societies (2nd JENS 2017, Venice Italy, Octb 3st - November 4th. 2017) and the abstract is published in the Journal of Pediatric and Neonatal Individualized Medicine 2017;6(2):e060238; doi: $10.7363 / 060238$ as a supplement of congress, Published online: 20170ct31.

\section{REFERENCES}

[1] Mayrovitz HN, Bernal M, Brlit F, Desfor R. Biophysical measures of skin tissue water: variations within and among anatomical sites and correlations between measures. Skin Res Technol 2013; 19(1): 47-54.

[2] Association of Women's Health, Obstetric and Neonatal Nurses (AWHONN). Neonatal Skin Care, Evidenced Based Clinical Practice Guideline. 3rd ed. Washington; 2013.

[3] Allwood M. Skin care guidelines for infants aged 23-30 weeks' gestation: a review of the literature. Neonat Paediatr Child Health Nur 2011; 14(1): 20-27.

[4] Hall K. Practising developmentally supportive care during infant bathing: reducing stress through swaddle bathing. Infant 2008; 4(6): 198-201.

[5] Loring C, Gregory K, Gargan B, LeBlanc V, Lundgren D, Reilly J, Stobo K, Walker C, ZayaTub C. Tub bathing improves thermoregulation of the late preterm infant. J Obstet Gynecol Neonatal Nurs 2012; 41(2): 171-179.

[6] Quraishy K, Bowles SM, Moore J. A protocol for swaddled bathing in the neonatal intensive care unit. Newborn Infant Nurs Rev 2013; 13: 48-50.

[7] Visscher M, Geiss S. Emollient therapy for newborn infants-a global perspective. Newborn Infant Nurs Rev 2014; 14: 153159.

[8] Medves JM, O'Brien B. The effect of bather and location of first bath on maintaining thermal stability in newborns. J Obstet Gynecol Neonatal Nur 2004; 33(2): 175-82.

[9] Varda KE, Behnke RS. The effect of timing of initial bath on newborn's temperature. J Obstet Gynecol Neonatal Nurs 2000; 29(1): 27-32.

[10] Baker B. Evidence-based practice to improve outcomes for late preterm infants. J Obstet Gynecol Neonatal Nurs 2015; 44: 127-134. 
[11] Cooper BM, Holditch-Davis D, Verklan MT,Fraser-Askin D, Lamp J, Santa-Donato A, Onokpise B, Soeken KL, Bingham D. Newborn clinical outcomes of the AWHONN late preterm infant research-based practice project. J Obstet Gynecol Neonatal Nurs 2012; 41: 774-785.

[12] Lyon A. Applied physiology: Temperature control in the newborn infant. Current Paediatrics 2006; 16: 386-392.

[13] McCall EM, Alderdice F, Halliday HL, Jenkins JG, Vohra S. Interventions to prevent hypothermia at birth in preterm and/ or low birthweight infants. Cochrane Database of Systematic Reviews 2010; 3:CD004210.

[14] Waldron S, Mackinnon R. Neonatal thermoregulation. Infant 2007; 3(3): 101-104.

[15] Visscher MO, Taylor T, Narendran V. Neonatal intensive care practices and the influence on skin condition. J Eur Acad Dermatol 2013; 27(4): 486-493.

[16] Butler CT. Pediatric skin care: Guidelines for assessment, prevention, and treatment. Dermatol Nurs 2007;19(5):471485.

[17] Blume-Peytavi U, Hauser M, Stamatas GN, Pathirana D, Bartels NG. Skin care practices for newborns and infants: Review of the clinical evidence for best practices. Pediatr Dermatol 2012; 29 (1):1-14.

[18] Maayan-Metzger A, Yosipovitch G, Hadad E, Sirota L. Effect of radiant warmer on transepidermal water loss (TEWL) and skin hydration in preterm infants. J Perinatol 2004; 24(6):372-375.

[19] Blume-Peytavi U, Cork MJ, Faergemann J, Szczapa J, Vanaclocha F, Gelmetti C. Bathing and cleansing in newborns from day 1 to first year of life: recommendations from a European round table meeting. J Eur Acad Dermatol Venereol 2009; 23: 751759.

[20] Bryanton J, Walsh D, Barrett M, Gaudet D. Tub bathing versus traditional sponge bathing for the newborn. J Obstet Gynecol Neonatal Nurs 2004; 33: 704-712.

[21] Garcia Bartels N, Mleczko A, Schink T, Proquitté H, Wauer $\mathrm{RR}$, Blume-Peytavi U. Influence of bathing or washing on skin barrier function in newborns during the first four weeks of life. Skin Pharmacol Physiol 2009; 22: 248-257.

[22] Kuller JM. Update on newborn bathing. Newborn Infant Nurs Rev 2014; $14 ; 166-170$.

[23] Nako Y, Harigaya A, Tomomasa T, Morikawa A, Amada M, Kijima C, Tsukagoshi S. Effects of bathing immediately after birth on early neonatal adaptation and morbidity: a prospective randomized comparative study. Pediatr Int 2000; 42: 517-522.

[24] Kim DY, Park HR. Effects of covering newborn's head after bath on body temperature, heart rate and arterial oxygen saturation. J Korean Acad Child Health Nurs 2012; 18(4): 201206.

[25] Edraki M, Paran M, Montaseri S, Nejad MR, Montaseri Z. Comparing the effects of swaddled and conventional bathing methods on body temperature and crying duration in premature infants: A randomized clinical trial. J Caring Sci 2014; 3(2): 83-91.

[26] Chiu SY, Huang HM, Tseng CY. Improving recovery of body temperature after ablution in premature infants. Hu Li Za Zhi J Nurs. 2007; 54(3):61-68. 